\title{
Implementing a Central Bank Issued Digital Currency with Economic Implications Considerations
}

\author{
Hazik Mohamed \\ Stellar Consulting Group, Singapore, hazik@stellarcg.com
}

Article History

Received: November 27, 2019 Revised: December 20, 2019 Accepted: January 7, 2020

\begin{abstract}
A central bank-issued digital currency $(C B D C)$ could solve the volatility of a privatelyissued cryptocurrency as well as keep intact its potential benefits. This research intended to analyze the possibilities for implementing a CBDC in a viable format that is also Shariah-compliant which may have the capacity to tackle issues plaguing the current financial system.

We discuss possible scenarios and the resulting impact and consequences of CBDC implementation, through a deep examination of the benefits, opportunities, costs and issues of several conceptual formats. Methodologically, we used qualitative, comparative and analytical assessments on the critical impact on crucial levers like dilution to monetary policy, and the stability of the financial system.

Finally, we found that the best format was a non-interest bearing CBDC for the interbank settlement and wholesale payment systems which would have the least disruption to the economy but strongest monetary policy transmission.
\end{abstract}

Keywords: Currency, Public Deposit, Policy Tool, Interbank Settlement.

JEL Classification: E58, E61, G20, O33

@ IJIEF 2020 published by Universitas Muhammadiyah Yogyakarta, Indonesia All rights reserved

DOI:

https://doi.org/10.18196/ijief.2121
Web:

http://journal.umy.ac.id/index.php/ijief/article/view/7582

\section{Citation:}

Mohamed, H. (2020) Implementing a Central Bank Issued Digital Currency: Assessing the Shariahcompliant Format. IJIEF: International Journal of Islamic Economics and Finance, 3(1), 51-74. DOI: https://doi.org/10.18196/ijief.2121 


\section{Introduction}

Customarily, the central authority that provides banks and other monetary organizations with electronic accounts for its functionality in the financial system is the Central Bank (CB). The public does not have such access and is only permitted to keep CB money in physical forms (i.e. coins and/or notes). If a $C B$ would issue a universal $C B D C$, all stakeholders (regardless if they are individuals, firms, institutions, governments and central banks) "could store assets and make payments using the Central Bank-issued digital currency" (Cerqueira et al., 2017). In consequence, this could have important shifts and repercussions for financial stability, monetary policy and the relation of economic actors to the financial system. There are not many papers in the literature (although there are some CBs already conducting research and pilot projects) that "address questions on the feasibility of a CBDC implementation, its impact on monetary policy, the financial sector and the economy" (Danezis and Meiklejohn, 2015; Rogoff, 2016; Barrdear and Kumhof, 2016). However, these research are descriptive or focused on regulatory frameworks and legal implications, while others are unable to define clear use cases and as a result confuse the implications of a possible CBDC deployment. The possible lack of actual implementation is due to the significant disruption caused to the existing monetary system without a clear understanding of its consequences and subsequent impacts.

\subsection{Objective}

The objective of this paper is to analyze the possibilities for implementing a CBDC in a viable format which is also Shariah-compliant that may have the capacity to tackle issues plaguing the current financial system. We discuss the possible scenarios and the resulting impact of CBDC on financial markets, monetary policy, on consumers, SMEs, banks and even central bank independence. In each format discussed, we describe the benefits, costs and incentives faced by stakeholders and end each format section with our assessment on the probability of adoption. Based on the four scenarios described in Cerqueira et al. (2017), we study the implications of each CBDC format. These formats are assessed separately in sections 1, 2, 3 and 4 broken down by their nature and projected impact, consequences and possible adoption assessment in terms of cost-benefit, feasibility and their overall effect on financial stability.

IJIEF: International Journal of Islamic Economics and Finance, 3(1), 51-74 | 52 
Mohamed | Implementing a Central Bank Issued Digital Currency: Assessing the Shariah-compliant Format

\section{Literature Review}

\subsection{Background Theory}

Cash is a financial instrument and tangible asset that exhibits four attributes: (i) it is anonymous (ii) it is universal (anyone can take possession); (iii) it is exchanged between individuals (or "peer-to-peer", without involvement of a central authority or the issuer) and (iv) it does not produce any interest by itself. CBDC is a digital alternative to cash that is also decentralized, but it gives more flexibility in the treatment of the other three features:

- They can be anonymous (like cash) i.e. the idea of token-based CBDCs, or identifiable (non-anonymous like current accounts) like account-based CBDCs.

- They can be unrestricted (universal) or restricted to a particular set of users. Likewise, distributed ledger (DL)-based tokens can be public (open) or private (closed), for instance, limited to banks or financial institutions.

- They can be designed to pay or not give returns (in absence of interest).

These options can be melded in different ways to generate useful formats of CBDCs for practical applications. Such amalgamation for purposeful solutions may involve these objectives: (i) to enhance the operations of wholesale payment systems; (ii) to replace or support cash with a more proficient substitute; (iii) to broaden and enrich tools for monetary policy transmission, particularly in overcoming the zero lower bound and (iv) to strengthen overall financial stability by decreasing the occurrences of banking and financial crises.

\subsection{Previous Studies}

Some earlier investigations found during the literature review attempted to understand the viability of a centrally-issued cryptocurrency and its possible implementation, its impact on monetary policy, and the subsequent effects on financial stability and the economy. Danezis and Meiklejohn (2015) noted that decentralization through a cryptocurrency has its benefits, such as independence from political control, but they also realized considerable constraints in terms of computational costs and scalability.

Rogoff (2016) in his Curse of Cash suggested to reduce the circulation of cash which, according to his findings, is "feeding tax evasion, corruption, terrorism, the drug trade, human trafficking, and the rest of a massive global

IJIEF: International Journal of Islamic Economics and Finance, 3(1), 51-74 | 53 
underground economy". He also showed that "paper money can also cripple monetary policy" due to falling interest rates (below zero) and still unable to stimulate the economy. In another study, Dyson and Hodgson (2016) recommend "an Indirect Access approach, in which a central bank (specifically the Bank of England) would still create and hold the digital cash, but all payment and customer services would operate through 'Digital Cash Accounts' (DCAs) provided by (or 'administered' by) private sector firms". Fung and Halaburda (2016) proposed a "framework for assessing why a central bank should consider issuing a digital currency and how to implement it to improve the efficiency of the retail payment system".

However, these research are descriptive or focused on regulatory frameworks and legal implications, while others are unable to define clear use cases and as a result confuse the implications of a possible CBDC deployment.

We have also focused our research on central bank-issued digital currencies because non-central bank-issued currencies have been volatile and do not make a good medium of exchange (unit of account and store of value too) when the value fluctuates quite drastically. Furthermore, cryptocurrencies are not legal tender if not issued by the central bank.

\subsection{Conceptual Framework}

For the purposes of discussion, the assumption is that the possible CBDC formats are maintained at a 1:1 parity with cash already in the economy. This assumption is held for all formats under discussion as uneven parity would create a series of aggravations and too many probabilities to ascertain any practical assessment.

Table 1. The four formats that are discussed in this research.

\begin{tabular}{|c|l|l|}
\hline Format & \multicolumn{1}{|c|}{ Use Case } & \multicolumn{1}{|c|}{ Characteristics } \\
\hline 1 & $\begin{array}{l}\text { CBDC as a Sovereign Currency } \\
\text { (similar to Cash/Fiat) }\end{array}$ & $\begin{array}{l}\text { Anonymous, universally-accepted } \\
\text { and non-interest bearing }\end{array}$ \\
\hline 2 & $\begin{array}{l}\text { CBDC as Public Deposit in } \\
\text { Central Bank }\end{array}$ & $\begin{array}{l}\text { Identified (non-anonymous), } \\
\text { universally-accepted and non- } \\
\text { interest bearing }\end{array}$ \\
\hline 3 & $\begin{array}{l}\text { CBDC as a Monetary Policy } \\
\text { Instrument }\end{array}$ & $\begin{array}{l}\text { Anonymous, universally-accepted } \\
\text { and interest bearing }\end{array}$ \\
\hline 4 & CBDC for Interbank Settlement & $\begin{array}{l}\text { Identified, restricted use and non- } \\
\text { interest bearing }\end{array}$ \\
\hline
\end{tabular}

IJIEF: International Journal of Islamic Economics and Finance, 3(1), 51-74 | 54 


\section{Methodology}

The methodology employed for this investigation into the four different use cases for the CBDC is a qualitative one, where we seek to determine its variation in application impact and to understand the relationships of each of the four formats with respect to being a cash substitute, their impact on monetary policy, on operations of wholesale payment systems and on the overall stability of the economic system.

\subsection{Model Development}

As we are still in early stages of consideration for a CBDC issuance and possible implementation, this research has adopted an overview approach to first qualitatively assess the critical impact on crucial levers like monetary policy, and the stability of the financial system as a result of the shifts from digital transformation. Although in section 5, we discussed Barrdear and Kumhof's (2016) investigations on the properties of a specific format of CBDC (Format 3 as described in section 4.3) using the DSGE model on the countercyclical monetary policy measures and interactions with fiscal policy, we felt that our approach provides a foundational understanding for the reader to grasp the different aspects of how the digital currency can be utilized to solve certain limitations to traditional policy instruments, and how introducing something new may impact the economy and in what way. This is particularly useful for policy-makers and central bankers who are unfamiliar with blockchain technology.

\subsection{Method of Assessment}

In order to assess CBDCs as cash substitute, their impact on monetary policy, on operations of wholesale payment systems and on the overall stability of the banking and financial systems, we had to qualitatively trace the repercussions that would result from such changes, with considerations to the current interactions with the existing cash, bank deposits and electronic money environment. As such each of the four formats will be assessed in three ways: by its expected impact, consequences, and adoption assessment.

IJIEF: International Journal of Islamic Economics and Finance, 3(1), 51-74 | 55 


\section{Results and Analysis}

\subsection{The CBDC as a Sovereign Currency (like Cash/Fiat Currency)}

This CBDC format retains all four features of cash: anonymity, peer to peer (P2P), universality, and non-yield bearing. Banks would remain as its creators and maintain their inimitability at keeping reserves at the $\mathrm{CB}$. Yves Mersch (2017) of the ECB, defined this CBDC format as "value-based" in collocation to an "account based" CBDC (analyzed later in Format 2 in section 4.4.2).

Anonymity in CBDCs would have the same issues with security and safety as cash. Like cash, stolen CBDCs would be hard to recover once stolen or lost, although CBDCs would be less likely to be stolen or lost than cash. P2P exchangeability allows its exchange between counterparties without intermediaries. Universality means that anybody can take possession of it, use and store it. Finally, this CBDC would not bear any yield just like cash.

\subsubsection{Impact and Consequences}

By virtue of the essential functions of money - "unit of account, medium of exchange and store of value" -the performance of the CBDC is assessed in the following paragraphs in relation to the most pertinent kinds of money: "bank deposits, cash and other private/foreign currencies".

As a "unit of account", the CBDC would be comparable to that of physical cash, as long as they remained pegged to each other ${ }^{1}$. This format is superior to private and foreign currencies because this CBDC currency would be digital hence effortlessly traded online. While current fiat currencies would remain vulnerable to exchange rate fluctuations on top of the risk of capital controls, the CBDC would not.

As a "medium of exchange", this CBDC format would both compete and complement both cash and bank deposits. However, it would remain an imperfect and also uncertain substitute for both because of required access and internet connection. Undoubtedly, its usage would increase as people become more familiar with online transactions and are more technologically savvy. Also, because it would retain anonymity², this format would not curb illicit transactions. "Compared to bank deposits, this format would facilitate

1 The implementation of this CBDC format would be like issuing a new "coin" or "note", although this note would be digital hence effortlessly traded online and infinitely divisible.

2 This format could even enable unlawful activities, as moving money becomes cheaper and easier than cash, although this may be unlikely considering that it is CB-issued, and there is a possibility of overturning anonymity in exceptional cases.

IJIEF: International Journal of Islamic Economics and Finance, 3(1), 51-74 | 56 
long-distance and/or large-quantity payments, but it would not necessarily offer additional services" ${ }^{3 "}$. Furthermore, "it would facilitate the offering of such services by firms other than banks-fintech companies and small players-thus further commoditizing the payment infrastructure and reducing the comparative advantage of deposits" (BIS, 2015).

In its function as a "store of value", CBDC persist to be riskier than bank deposits (in this format), at least up to the amount guaranteed by authorities. With no traceability, anonymity becomes a liability if it were stolen, lost or the password (to the wallet) forgotten. According to Broadbent (2016), "if all CBDC did was to substitute for cash .... people would probably still want to keep most of their money in commercial banks" simply because it is familiar and there is a custodian for safe-keeping.

The introduction of this format would impede cash usage and potentially diminish (but not severely) bank deposits. Physical cash would still dominate in economies where transactions are cash-driven but in increasingly cashless societies where cash transactions are dwindling, CBDCs would swiftly replace cash.

As a means of exchange, the total advantages of this format would compensate for its costs. CBDC in this format is digital cash without the volatility and price instability of current non-government crypto-currencies, such as Bitcoin (BTC), Ethereum (Ether), Ripple (XRP). The advantages of currencies like Bitcoin, Ethereum, Ripple is in the faster money transfers (and cheaper too) that would also benefit CBDC holders by turning these advantages to productive gains (Barrdear and Kumhof, 2016). Financial inclusion can be advanced, especially where it is difficult for banks to establish branches due to geographical remoteness or where physical cash are ineffective compared to digital versions (IMF, 2019). In ASEAN, the ASEAN Financial Innovation Network (AFIN) "aims to facilitate broader adoption of fintech innovation and development in the region". According to a January 2019 from the Bank of International Settlements (BIS, 2019), 70\% of central banks (based on 63 central banks that participated in the survey) are currently researching the issuance of a CBDC. The majority of the countries currently investigating to launch of a digital currency, cited 'financial inclusion' as the main reason for exploring CBDCs.

For consumers and businesses, transactional settlements and fund transfers become faster and cheaper since accessibility becomes easy to perform these transactions (Cerqueira et al., 2017). This feature is particularly useful for developing countries, as remote and rural areas have accessibility

3 It is highly unlikely that CBs would provide Fl-type financial services, despite certain types of services
can be inherent to a CBDC through a tech-centric platform as opposed to a bank-centric one.

IJIEF: International Journal of Islamic Economics and Finance, 3(1), 51-74 | 57 
Mohamed | Implementing a Central Bank Issued Digital Currency: Assessing the Shariah-compliant Format

challenges. Savings would also be improved since the CBDC as an instrument would allow money to be stored effortlessly.

Also, the gains would likely outweigh the outlays for central banks and monetary authorities. Higher efficiency gains would be obtained from emerging markets with high inflation, where maintenance and issuance of physical cash have become costly. Furthermore, this format will aid monetary authorities to become competitive and limit the use of private or foreign digital currencies which they do not control. Importantly, CBDC strengthens monetary policy transmission mechanism in that it brings the latter closer in line with the objectives of monetary policy. However, the authorities will have to bear all the costs required to implement and maintain the new infrastructure along with first hand equipment and the hiring and training of new skills.

Unfortunately for the banking industry, the expense will exceed the gains. The CBDC would make intermediaries (like banks) for payment transactions unnecessary, ending the payment business ${ }^{4}$ for banks. The payment services would then be just an auxiliary part of an encompassing service of financial management.

Due to the partial substitution of CBDC for deposits, banks' credit business would deteriorate too. As the volume of deposits drops, so does the money multiplier. Also, as the deposits in the banking system fall, their volatility increases due to wealth reallocation from deposits into a broader range of riskier alternatives. With increased volatility, asset and liability management by banks would become more intricate. In addition, the banks would lose critical data that they use to draw up credit scores based on consumer wealth and repayment behaviors.

The potential benefits for banks would likely arise from the easing of banking regulations as the sector become less strenuous and their activities become less disruptive to the financial system. Potential benefits might ensue from new business opportunities facilitated by $\mathrm{CBDC}$, such as the management and protection of the keys for CBDC wallets, although it is more likely that this will be adopted by banks themselves.

\footnotetext{
4 Faced with bank fees (no matter how minimal), even people who prefer traditional accounts would consider converting their deposits to frictionless CBDC for more efficient payments. International transfers are already affected.
}

IJIEF: International Journal of Islamic Economics and Finance, 3(1), 51-74 | 58 


\subsubsection{Adoption Assessment}

The elimination of cash, or at least a partial elimination as suggested by Rogoff (2016) is always an option, and only low-denomination bills and coins are preserved. Such possibility is particularly significant under this format, as the $\mathrm{CBDC}$ replaces physical cash, although in high amounts only.

It would be easier to eradicate cash in developed economies where most transactions are already digitalized, but in cash-dependent economies, it is more challenging. Eliminating cash could save bank fees but create other costs for end users, although they would enjoy social benefits from the reduction in unlawful transactions. Although the CBDC remains anonymous, there is a possibility that obscurity can be reversed at any point for AML/CTF investigation purposes. Such possibility makes this CBDC format unappealing for illicit activities, like tax evasion, etc.

Using CBDC in this format equates to enhanced efficiency in payments and money transfers, reducing transactional costs. For the finance industry, as security measures to safeguard e-wallets (on top of safeguarding passwords), new businesses could emerge based on this type of service. The reduction in deposits will cause an immediate drop in the amount of credit granted or an increase in the cost of credit, if there are no CB compensatory measures or stabilization policy. In such a scenario, financial stability and the credit markets may be negatively affected.

\subsection{The CBDC as Public Deposit in Central Bank}

This format generates a very disruptive configuration of CBDC because it proposes an identifiable money which is non-anonymous. Practically, "having a CBDC held by the general public is the equivalent of keeping a deposit in the central bank, so that the authority's power to supervise and monitor it would be substantially greater than it is today" (Cerqueira et al., 2017). Being identifiable and non-anonymous, non-compliant activities can be detected. As a deterrent and a regulatory tool in combating illegal activities, it would require the eventual elimination cash and limit the use of alternative assets for this CBDC format to be absolutely effective, which is not easy to do. Two possible scenarios for the adoption of a CBDC with these characteristics have two main differentiating and important elements.

In the first scenario, particularly in countries where there is a high volume of illegal activities-such as attempts to launder money and evade taxes-makes the adoption of this CBDC format useful for the government. In the second scenario, $\mathrm{CBDC}$ as a recognized conversion of deposits in the

IJIEF: International Journal of Islamic Economics and Finance, 3(1), 51-74 | 59 
Mohamed | Implementing a Central Bank Issued Digital Currency: Assessing the Shariah-compliant Format

banking system into deposits in the Central Bank, can offer greater financial stability to the country.

However, the consequent reduction in bank deposits would shrink credit markets significantly, as falling bank deposits would mean that credit creation becomes severely limited. Since every deposit would be accounted against sovereign wealth (i.e. cash, central bank reserves and government securities), this format facilitates a full-reserve banking (FRB) system. FRB endeavors to "separate the payments system from the financing system as well as monetary policy from credit policy" (Laina, 2015). Preventing private money creation would ensure financial stability as initially proposed in the UK Bank Charter Act of 1844, the US Acts of 1863 and 1864, the Chicago Plan of 1930s forbade "private money creation through fractional-reserve banking by requiring that bank notes (which were the prevailing means of payment) should be fully-backed by government money". This format opens a discussion on allocating government-backed liquidity and the conditions that the CB could benchmark to build up liquidity in the banking system with framework adjustments for reserves and/or open market transactions.

\subsubsection{Impact and Consequences}

A non-anonymous CBDC format would make it less appealing than cash as a medium of exchange, at least for some. But the demand will rise for such CBDCs as it is a more efficient means of exchange. In comparison with other CBDC formats namely as a sovereign currency (Format 1 discussed in section 1.0) and as a monetary policy tool (Format 3 discussed in section 4.3.), this format would be less desirable as an exchange medium.

However, as a store of value, this CBDC format would be highly desirable because it is a safer form of money as compared to other formats. It will be a safer from technological issues and because it is identifiable (nonanonymous), it will be easier to recover in cases of loss, theft, etc. Moreover, it will be a safer than bank deposits, as the maintenance risks at the CB are clearly lower than as deposits in a bank. Some would still demand bank deposits due to higher remuneration and services, but banks would prefer higher credit levels in a fractional reserve system for higher profitability.

Deposits at the $\mathrm{CB}$ are much safer than bank deposits, among other things, because they do not bear any credit risk. Due to that feature of CBDC deposits, this is comparable to keeping deposits in a purported "narrowbank" model, i.e. in a "financial institution that is compelled by authorities to maintain the public's resources under custody in a liquid and safe form, such as in government bonds, rather than leveraging on them in order to create

IJIEF: International Journal of Islamic Economics and Finance, 3(1), 51-74 | 60 
Mohamed | Implementing a Central Bank Issued Digital Currency: Assessing the Shariah-compliant Format

credit" (Kotlikoff, 2010). This would likely lead to a narrow-banking system due to $C B$ accepting CBDC deposits and making CBDC non-anonymous.

Despite having this format and the CB functioning broadly as a narrow-bank, existing banks will continue to function as "fractional-reserve banking" models, i.e. "transforming part of the public's deposits into credit and keeping only a fraction of them as reserves". In this way, we can refer to this format as a partial limited-purpose banking system, as opposed to a full narrow-banking system where financial institutions are also required to operate as stable narrow-banks rather than as fractional-reserve banks that is less stable systemically.

From the monetary authority perspective, the demand increase for CBDC equates to the increase in the size of the $C^{\prime}$ 's liabilities, hence increasing the size of its balance sheet. The $C B$ will then increase its assets through purchase of predominantly safe and liquid assets, such as GDP-linked bonds, treasury bills and public securities, to counterbalance CBDC deposits, in order to match the increase in its liabilities.

\subsubsection{Adoption Assessment}

CBDC in this format will "work as a proper unit of account, like cash and bank deposits, and in contrast with private and foreign currencies" (Cerqueira et al., 2017). In this particular format, "the CBDC will be in general a better store of value and a worse medium of exchange" than in other formats, its adoption will very much depend on how the government and its people value financial stability, safety and anonymity.

On a cautionary note, the deposits that the CB obtains with a recognized $\mathrm{CBDC}$ should not be used to either grant loans to the non-financial private sector or finance governments. First off, it would be problematic as $C B$ is not meant to do so and a non-independent CB could, for example, compete with banks for more deposits, and lose its focus on its original objectives as a market supervisor and regulator. Although this format may reverberate changes to a more financially-sound and stable system, like all systems, its moral risks remains. In the guise of improving financial stability, moral hazards include unscrupulously generating unreasonable incentives for the government, increasing the risks of fiscal slippage, and creating problems for the $C B$ with regards to its independence.

IJIEF: International Journal of Islamic Economics and Finance, 3(1), 51-74 | 61 


\subsection{The CBDC as a Monetary Policy Tool}

In this format, the proposed digital currency bears semblance to cash (being universal and anonymous) in some ways "but with the special feature of possibly being interest-bearing" (Cerqueira et al., 2017). "An interest-bearing currency as a monetary policy instrument gives the Central Banks autonomy to meet their inflation targets, by dropping the nominal value of the digital currency", similar to reducing the interest rates without any lower bound (refer to Barrdear and Kumhof (2016) or the following section 5.0). Analogously, the nominal value of the CBDC would rise if there is a rise in interest rates, causing an increase in the monetary base. In such a format, monetary policy would be transmitted directly, thus accelerating the transmission of this policy whilst creating unlimited room for action to meet inflation targets without having to depend on the banking system as a proxy transmission channel to the economy. As a consequence, the effectiveness of monetary policy is enhanced considerably. Under the present configuration of monetary policy transmission mechanism, the banks have a crucial role in the effectiveness of this mechanism. It should be noted that the aim of monetary policy is to prompt adjustments in the private sector's portfolio (investment and consumption) in order to achieve stability. However, the banking system and monetary policy have two different objective functions. The former maximizes profits while the latter's objective is to achieve financial stability to help growth. More often than not, the two are in conflict. Current monetary policy relies on the banking system to transmit its actions to the private sector to induce it to adjust its portfolio to achieve monetary policy objective(s). As the objective of monetary policy comes into conflict with that of the banking system, more than likely that the banking system will serve its own objectives, thus, reducing the strength of monetary policy transmission and thus rendering monetary policy actions impotent. As mentioned, CBDC in this format has the capacity to reduce the dissonance from the banking system while, concurrently, enhancing the power of monetary policy transmission mechanism by directly inducing private sector portfolio adjustments.

\subsubsection{Impact and Consequences}

It is possible to create $\mathrm{CBDC}$ with smart contracts that can change the face value of the whole stock of $C B D C$, effectively transforming the CBDC into an interest-bearing currency. An interest-bearing currency would be a radical shift that could create possibilities for monetary policy that are currently unavailable, and difficult or costly to implement.

IJIEF: International Journal of Islamic Economics and Finance, 3(1), 51-74 | 62 
Being able to change (particularly to decrease) the face value of a national digital currency is equivalent to being able to set interest rates as low as is required (even as negative as necessary) without being constrained by any "zero lower bound". This would allow CBs to respond assertively against recessionary economic pressures. Inversely, increasing the face value of the currency will positively cause an expansion in the monetary base.

However, being able to do it technically does not equate to wanting to do it politically or strategically. Empowering CBs to decrease the face value of circulating currency can be wickedly construed as expropriation. Although expropriation in real terms happens via economic inflation and quite regularly too, it is not clear how society would react to a minimal sequestration of wealth via monetary policy. In terms of legitimacy, when CBs are empowered to vary the face value of circulating currency, it effectively tantamount to adjusting the wealth of those holding the currency. In the existing economic system, this is traditionally the sanction of the fiscal authority, not the monetary authority. By varying interest rates, it raises legitimacy issues for CBs to transmit fiscal policies, or at least a new discussion on a modified or merged function. Moreover, the currency becomes a questionable numeraire ${ }^{5}$ as a unit of account in the market when CBs have control over its face value.

This CBDC format retains anonymity, P2P and universality. But unlike cash, this CBDC format can bear interest. An important point to note is that the interest rate of the CBDC can be different from the monetary policy interest rate. The different yields could weaken the efficiency of monetary policy transmission but, a lower interest rate would afford more flexibility for banks to incentivize deposits above the CBDC rate than the official interest rate, which could protect both financial stability and credit markets.

The coexistence of cash and CBDC under this format would be complicated and somewhat thorny. If interest rates were negative, people would convert their CBDCs to zero-yield physical cash to safeguard its value, and CBDCs would logically only sustain significantly negative rates only if all physical cash were abolished. If the CBDC bore positive rates instead, then people would change their cash into CBDCs, and in doing so, transforming itself to a cashless society.

As in the first format (CBDC as a Sovereign Currency), this "CBDC would exhibit advantages in comparison to bank deposits, especially when viewed as a medium of exchange without intermediaries" (Cerqueira et al., 2017). However, "bank deposits would likely keep their advantage as a store of value (better safeguards) and continue attracting those looking for specific

5 an item or commodity acting as a measure of value or as a standard for currency exchange. 
banking services. As a result, the demand for bank deposits relative to that for CBDC would depend on the yield spread between them" that gives better value. But intuitively, any volatility would be higher as the spread between CBDC and deposits would be fluctuating at both of its margins ${ }^{6}$.

In this form, CBDC still competes with other currencies and assets. In deciding which form of currency to hold, the value and the perceived stability of CBDCs versus other currencies/assets would be crucial in the demand for CBDC. Viewed from exchange rates between currencies, it is no different to what we have today, where floating rates of currencies coexist while preserving their own domestic interest rates. Yet uncertaintyinstability might intensify with negative rates, making CBs forced to impose capital controls as a last resort?

According to the BIS (2018), "CBDCs are considered an autonomous factor for monetary policy implementation for two reasons. First, from the viewpoint of the day-to-day steering of the central bank's balance sheet to control short-term interest rates, daily fluctuations in the demand for CBDC are an exogenous factor, even though CBDC would be an endogenous factor within the broader monetary policy framework. Second, even if CBDC was introduced, the amount of digital central bank money held by monetary counterparties (reserves) would still be crucial for control over short-term interest rates".

\subsubsection{Adoption Assessment}

In principle, this format would allow the $\mathrm{CB}$ to implement negative interest rates, which would incur losses in value for these CBDC holders, equivalent to sequestration. In addition, users can possibly be identified due to technological breach or legal requirement, at the costs of still not having cash in hand. In addition, any internet disruption or power shortage would also magnify the costs of the abolition of cash. Conversely, positive rates would be a welcomed option as it would improve CBDC value for the holders.

If cash (sovereign fiats) were to be replaced, authorities would bear the high cost of accessibility to this new CBDC, both in educating the global public as well as reducing technology barriers concerning its use. Further, it is intuitive

\footnotetext{
6 As suggested before, CBDC interest rates could be set at a sufficiently low level such as to guarantee that demand for bank deposits does not fall significantly, driving credit levels down.

7 Uncertainty might rise because CBs are only held accountable for keeping inflation under control (and their credibility on that front has led to stability in international exchange markets). However, central banks are not held accountable for sustaining rates above any level.
}

IJIEF: International Journal of Islamic Economics and Finance, 3(1), 51-74 | 64 
and important to discuss what the $\mathrm{CB}^{\prime} \mathrm{s}$ roles ${ }^{8}$ and mandates are before allowing CBDCs to yield interests, and then to establish a framework to correctly incentivize major stakeholders. Further considerations will be made to comply to Shariah which forbids interest in Islamic nations.

Finally, the cross-border payments transactions could be considerably diminished by any possible adoption of capital controls. Domestically, payment services would practically come to an end with the elimination of cash, as in Format 1 (section 4. 1.) which replaces cash.

\subsection{The CBDC as Interbank Settlement}

The "current settlement of payments is costly because it needs strict monitoring to avoid any double spending or sudden default. As a result, payment systems currently used by CBs are tiered: only Tier1 banks can open a settlement account in the CB (which needs to remain continuously funded) for immediate settlement purposes. Banks in other tiers have to open accounts in Tier1 banks and go through them to settle their transfers in the CB. Thus, top-tier banks intermediate other banks' transfers while also managing their own customers' accounts" (Cerqueira et al., 2017).

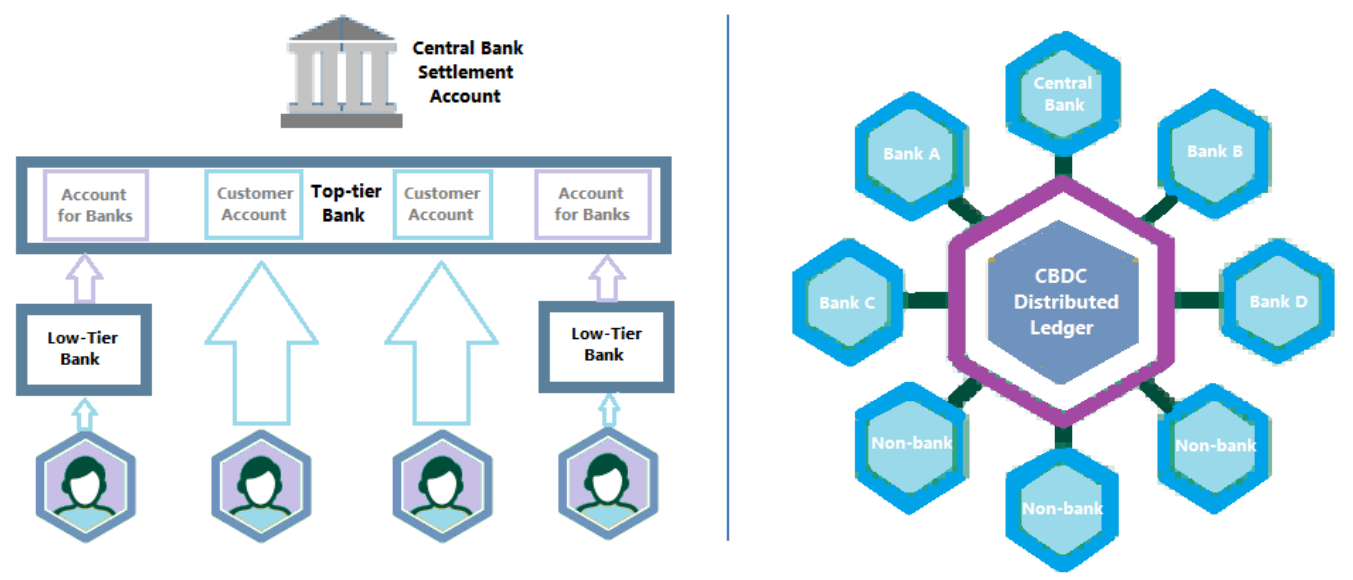

Figure 1. Tiered Payment Model versus Distributed Payment Model

8 Although changing the face value of a currency seem similar to changing its yield, there is an important dissimilarity when effecting such a change as a policy lever. In normal CB operations, interest rates are typically adjusted in open market operations by changing their total balance. In this format, reducing the face value of CBDC implies the reduction of the CB's liabilities without a corresponding fall in its assets and conversely, increasing the surplus (or reducing the deficit) of the consolidated fiscal account.

IJIEF: International Journal of Islamic Economics and Finance, 3(1), 51-74 | 65 
Mohamed | Implementing a Central Bank Issued Digital Currency: Assessing the Shariah-compliant Format

For this format, the current interbank payment system is replaced with a DLT-based infrastructure, so that the participants' accounts in the Central Bank are replaced by $\mathrm{CBDC}$ wallets and the $\mathrm{CB}$ becomes merely another node in the network (see Figure 1), albeit with regulatory concessionsretrieve information on all the transactions as a market supervisor. CB can decide who participates in the system and is the sole cryptocurrency issuer. The "main advantages of this scenario lie, on the one hand, in the increased efficiency of the interbank payment system (i.e. cost reduction and speed increase)" (BIS, 2018). On the other hand, "in the greater resilience of a system of this type to cyberattacks since there is no vulnerable central point. The less efficient and insecure the system is, the greater the net benefits of adopting a CBDC" (BIS, 2019), making up for the implementation costs of new substructure, and adoption more likely.

\subsubsection{Impact and Consequences}

This format achieves what modern payments systems set out to do-P2P and more rapid payments, and involving fintech companies (or other NBFIs) which have the expertise but not necessarily focused in banking services. This would separate the financial business of credit and payments, where payments now can become commoditized through innovation for better services and use. Overall, all parties, including consumers, will benefit from faster, better and cheaper services from the efficiencies gained.

The creation of a shared payments ledger system would allow for real-time and traceable transactional information about capital flows, which is progressing towards dynamic scrutinizing and better handling of systemic risk. Furthermore, the $\mathrm{CB}$ will have to compete with other digital currencies/ledgers $^{9}$ in order to keep full-control (supervision) of the settlement system. In fostering competition, it will expand accessibility without incurring traditional payment infrastructure costs. The marginal cost of adding a new participant would be considerably lower which is done by simply adding a new node to the network. Allowing more players to have direct entry to the wholesale payments business would increase competition, but these benefits can only be realized at a high initial cost of application $^{10}$ and subsequent maintenance costs after implementation (although these are lower than present systems).

\footnotetext{
9 In this research, other digital currencies are defined as those not issued by the CB, like Libra, Bitcoin, etc.

10 Implementation costs include the development of new skills needed in CBs in order to be able to make full use of data stored in the ledger.
}

IJIEF: International Journal of Islamic Economics and Finance, 3(1), 51-74 | 66 
Mohamed | Implementing a Central Bank Issued Digital Currency: Assessing the Shariah-compliant Format

However, "Tier1 banks would lose their privileged role as ultimate settlers in $\mathrm{CB}$ accounts, and would lose part of the payment business in favor of Tier2 banks, and all of them in favor of non-banks. Additionally, direct access to the wholesale payments settlement system would allow non-banks to provide end-to-end payment services and, as a consequence, increase their market share. Such new entrants might negatively impact the revenues of banks. However, the benefits in terms of efficiency, infrastructure costs savings, resilience, transparency and innovation could well outweigh such loss of revenue" (Cerqueira et al., 2017).

With new competition, this format would drive "banks to focus on the credit business, where their expertise in risk management and the resources needed to enter into the business" are their competitive advantages. But looking at how banks have adopted fintechs to protect their market share, cooperative partnerships and collaborations between banks and the new techfin $^{11}$ entrants or other fintech companies will naturally develop, to complement knowledge, processes and skills in payments and credit services.

Operationally, the management of consumer liquidity via their CBDC wallets is a departure from the traditional overdraft sequence to topping up of wallets in a DL-based system. CB settlement accounts in RTGS today are quite similar, as they are "periodically pre-funded with accurate calculated funds enough to cover the payment needs". However, in this situation, banks need to balance the amount of $\mathrm{CB}$ money both in its traditional form and in CBDC at all times.

For central banks, the "utilization of a DL-based infrastructure allows for the full availability (365 days a year, 24 hours a day, 7 days a week) of the system, which can operate without interruption, unlike current RTGS systems, such as TARGET2 in Europe, which have predetermined operating schedules". In addition, a decentralized system is much more robust to hacks and cyber-attacks than the current online systems because there is more than a single point of attack in order for it to fail.

For banks, the main benefits would be similar to those of the CB: 24-7 accessibility and security against threats and attacks, besides being faster and cheaper in the whole settlement process, and that includes its new infrastructure costs. Due to tougher competition, transaction fees will drop to more precisely indicate the marginal cost of verification related to payments.

11 Fintech is a financial technology company whereas techfin is a primarily technology company that is venturing into financial services.

IJIEF: International Journal of Islamic Economics and Finance, 3(1), 51-74 | 67 
Mohamed | Implementing a Central Bank Issued Digital Currency: Assessing the Shariah-compliant Format

From the payment aspect, business competitiveness would shift from merely payments itself to the evolution of additional consumer services. The transactional part of payments can be afforded by any financial service provider since they now have direct access to the decentralized settlement system. As such, the successful provider of the payment business would then seamlessly and intuitive create a strong user experience through wideranging value-added services, primarily built upon the payment insights retrieved from transactional data. Despite not being able to access CBDCs directly in this scenario, end-users (i.e. the customers) would benefit from cheaper, safer and faster money transfers.

A report from the IMF notes that "one area where there is a huge potential for efficiency gains is in cross-border payment systems" (IMF, 2017). They believe that "cryptocurrencies offer an opportunity for dramatic cost reductions, which may translate into faster and less expensive transactions, for instance in remittances". Being national payment systems, CBDCs may compete with cryptocurrencies in remittance transactions, or develop interconnected payments systems between nations for cross-border transactions to vie for preference over privately-issued cryptocurrencies.

\subsubsection{Adoption Assessment}

This CBDC format is amply favorable because of its benefits and could serve as an intermediate step to start testing the more disruptive scenarios of formats 1, 2 and 3. CBs such as "the Bank of England are currently working on modernizing their RTGS systems, and a DL-based infrastructure is being seriously considered", as reported by BBVA Research (Cerqueira et al., 2017).

IJIEF: International Journal of Islamic Economics and Finance, 3(1), 51-74 | 68 


\section{Further Analysis}

\subsection{Countercyclical Measures and Fiscal Policy Interactions with CBDC}

In another study, Barrdear and Kumhof (2016) of the Bank of England investigated the properties of a specific format of CBDC (Format 3 discussed in section 4.3) which "can be held by the non-bank private sector" (unlike reserves), that it is bears yield (unlike cash), and that it rivals the "internally created private bank-issued money". Their quantity or price rules react to inflation, in the same way it responds to the policy rate ${ }^{12}$. Hence, the quantity and price rules for CBDCs have a "very similar potential for countercyclical policy responses to standard shocks" (discretionary monetary stimulus or money supply shock). The "choice between quantity and price rules must therefore mostly be based on the fact that price rules, as mentioned above, perform better under money demand shocks". Barrdear and Kumhof (2016) also found that "the relative performance of countercyclical quantity and price rules depends critically on the elasticity of substitution between CBDC and bank deposits, with a lower elasticity implying that smaller quantity responses and larger interest rate responses to inflation are required to achieve the same degree of countercyclicality".

In order for the "CBDC price rule and countercyclical quantity rule" to be sufficiently effective, Barrdear and Kumhof held the assumptions that the steady state quantity of CBDC amounts to $30 \%$ of GDP (sufficient to render substantial withdrawals of CBDC possible "without hitting a 'quantity zero lower bound'"), that the CBDC is used frequently enough by its prospective users, and that the "steady state efficiency gains of CBDC issuance" are sizeable over the expected scale measured.

Within this model, Barrdear and Kumhof found that a "system of CBDC offers a number of clear macroeconomic advantages, including large steady state output gains of almost 3\% for an injection of CBDC equal to $30 \%$ of GDP", and considerable "gains in the efficacy of systematic or discretionary countercyclical monetary policy". Their analysis suggests that the only restrictions required to obtain these gains are that an adequately large supply of $\mathrm{CBDC}$ is circulated in steady state, and that the central bank only utilizes the CBDC when it trades against government debt instruments.

\footnotetext{
12 They visualized that the "CBDC would be an economically relevant monetary aggregate as long as the quantity outstanding is sufficiently large and its substitutability with other monetary transactions media is sufficiently low".
}

IJIEF: International Journal of Islamic Economics and Finance, 3(1), 51-74 | 69 


\subsection{Further Economic Implication Analysis and Recommendations}

From the formats that have been ruminated, Format 4 (described in section 4.4.) appears to be the least disruptive to the existing system. The benefits are extensive in terms of operations from the banking, payments and "huge potential for efficiency gains is in cross-border payment systems". And rightly so, many central banks are at present looking into this particular format to venture and experiment with. In terms of ranking, Format 3 (described in section 4.3.) would be recommended next, as it has the potential to generate steady state output and efficiency gains unique to the CBDC as a monetary policy tool albeit with certain essential conditions. Among the attractive advantages is its ability to overcome the 'quantity zero lower bound' issue. Formats 1 and 2 could be implemented at later stages after Formats 4 and 3.

However, the interest rate as the pricing mechanism and policy lever here then requires a little more in-depth discussion, considering the Shariah perspective. It is intended to explain the Islamic financial perspective which effects a ban on interest, including interest rate as a pricing mechanism. The concern for justice and equity involves nondiscriminatory exchange and fairness in financial transactions, including getting the market prices right through proper pricing mechanisms so as to not suffer the consequences of mispricing.

'Getting the prices right' means letting market forces function naturally to produce market prices that reflect all opportunity costs that correspond to them. John Maynard Keynes (1932) had already indicated that "the interest rate policy had deviated the true opportunity cost of financial resources", and James Tobin (1969) pointed out that "there was no such thing as a 'market rate of interest' in an environment in which policy drove the 'market rate of interest"." "Monetary policy had the ability", Tobin argued, "to force a deviation between market valuation of capital and its replacement cost". His "fundamental-valuation efficiency" concept, interpreted as "allocative efficiency", would ascertain the opportunity cost of financial resources that guides and necessitates their worthiest uses.

In 'getting the prices right' dogma, a market where prices were not allowed to reflect their opportunity cost, becomes repressive to market players - which "was the McKinnon-Shaw argument for liberalization of the financial sector of developing countries" (Mirakhor, 2017). Financial repression, the deviation of "administered interest rate" from the "market interest rate", led to market distortions, which has resulted in poor savings, inadequate investments and stunted economic growth. In the subsequent decades of financial liberalization to chase economic prosperity, Mirakhor laments that "a basic question never asked was how and in what sense did

IJIEF: International Journal of Islamic Economics and Finance, 3(1), 51-74|70 
Mohamed | Implementing a Central Bank Issued Digital Currency: Assessing the Shariah-compliant Format

the 'market rate of interest' reflect the true opportunity cost of financial resources".

One of the central problems of major economies, according to Mirakhor, "is the uncoordinated and mismatched balance sheets of the real, financial, household and government sectors". Ideally, the assumption is that the market would work freely to coordinate the balance sheets and allow for equilibrium to surface. Unfortunately, the current state of economics suffers from a runaway financial sector, which is decoupled from the real sector. In its current state, the economy only apportions a miniscule amount of market trades to capital formation in the real sector resulting in a real sector with corporations overflowing with cash, but not investing. With reduced investments, MSMEs become starved for financial resources, and unable to grow and survive, while government sectors amass huge debts to fund their programs, unable to coordinate its balance sheets. The market's inability has spawned a "paper economy" without much connection to the real sector, when in fact, the economy needs a real sector rate of return to replace the mis-pricings of opportunity cost of financial resources in order to productively allow capital to circulate. 


\section{Conclusion and Recommendation}

\subsection{Conclusion}

For CBDCs to be practical, it has to provide pragmatic implementable solutions that will solve existing problems that cannot be solved by current tools or instruments. Current policies and frameworks will remain ineffective to existing problems so long as fundamental flaws which are systemic are not rectified. They cannot be resolved by "patch" solutions which only treat symptoms (not the root) where increasingly outdated and flawed mechanisms have masked their compounding detrimental effects. DL-based solutions like the CBDC in its various formats offer alternatives in tackling some of these important issues as we work towards a freer marketplace, a more stable financial and considerably more prosperous economic system.

\subsection{Recommendations}

To possibly rectify and rise from a "paper economy" without much connection to the real sector, a properly-researched CBDC can at least enhance the effectiveness of the tools of monetary policy. Where the interest rate mechanism is no longer available to allocate (better said, misallocate) financial resources, as would be the case in Islamic finance, monetary policy becomes even more effective in inducing private sector portfolio adjustment as it relies on the rate of return to investment in the real sector of the economy (as the true opportunity cost of financial resources) to guide its policy actions. Such systemic change is required for a systemic problem that has gone on for far too long.

For further research, central bank researchers and policy-makers can test these scenarios (CBDC formats) using the DSGE model since monetary DSGE models are widely used because they fit well with the such data well and they can be used to address important monetary policy questions (Christiano et al, 2010). Policy analyses with DSGE models requires data being assigned numerical values to model parameters.

\section{Acknowledgement}

The author would like to thank Professor Abbas Mirakhor for his invaluable inputs and suggestions.

IJIEF: International Journal of Islamic Economics and Finance, 3(1), 51-74| 72 
Mohamed | Implementing a Central Bank Issued Digital Currency: Assessing the Shariah-compliant Format

\section{References}

Agarwal, R., \& Kimball, M. (2015). Breaking through the zero lower-bound, IMF Working Paper, WP/15/224.

Bank for International Settlements (2019). Proceeding with caution - A survey on central bank digital currency, Monetary and Economic Department, January 2019.

Bank for International Settlements (2018). Central bank digital currencies, Committee on Payments and Market Infrastructures, March 2018.

Bank for International Settlements (2015). Digital currencies, Committee on Payments and Market Infrastructures, November 2015.

Barrdear, J., \& Kumhof, M. (2016). The macroeconomics of central bank issued digital currencies. Staff Working Paper No. 605, Bank of England.

Bogle, J. (2012). Clash of cultures: investment vs. speculation. John Wiley \& Sons, Hoboken, New Jersey.

Cerqueira, G., Dos Santos, E., de Lis, S., Neut, A., \& Sebastián, J. (2017). Central bank digital currencies: Assessing implementation possibilities and impacts. BBVA Research, March 2017.

Christiano, L., Trabandt, M., \& Walentin, K. (2010). DSGE models for monetary policy analysis. NBER Working Paper No. 16074, June 2010.

Danezis, G., \& Meiklejohn, S. (2015). Centrally banked cryptocurrencies. University College London.

Dyson, B., \& Hodgson, G. (2016). Digital cash: Why central banks should start issuing electronic money, Positive Money.

Fung, B., \& Halaburda, H. (2016). Central bank digital currencies: A framework for assessing why and how. Bank of Canada Staff Discussion Paper No. 2016-22.

IMF (2019). Fintech: The experience so far. IMF-WBG Policy Paper, June 2019.

IMF (2017). Fintech and financial services: Initial Considerations, IMF Staff Discussion Note, SDN 17/05.

Koning, J. P. (2016). Fedcoin: A central bank-issued cryptocurrency. November 15, 2016.

Kotlikoff, L. (2010). Jimmy Stewart is dead: Ending the world's ongoing financial plague with limited purpose banking. John Wiley \& Sons, Hoboken, NJ.

Laina, P. (2015). Proposals for full-reserve banking: A historical survey from David Ricardo to Martin Wolf. University of Helsinki.

IJIEF: International Journal of Islamic Economics and Finance, 3(1), 51-74| 73 
Mohamed | Implementing a Central Bank Issued Digital Currency: Assessing the Shariah-compliant Format

Mersch, Y. (2017). Digital base money: An assessment from the ECB's perspective. Speech at the farewell ceremony for Pentti Hakkarainen, Deputy Governor of Suomen Pankki - Finlands Bank. Helsinki, 16 January 2017.

Mirakhor, A. (2017). Islamic finance and financial repression. https://journal.wahedinvest.com/islamic-finance-and-financialrepression/ Accessed 5th July 2019.

Pfister, C. (2017). Monetary policy and digital currencies: Much ado about nothing? Bank of France, Working Papers, no 642.

Raskin, M., \& Yermack, D. (2016). Digital currencies, decentralized ledgers, and the future of central banking, NBER Working Paper No 22238, May 2016.

Rogoff, K. (2016). The curse of cash, Princeton University Press.

Stevens, A. (2017). Digital currencies: Threats and opportunities for monetary policy, National Bank of Belgium, Economic Review, June.

Sveriges Riksbank (2017). The Riksbank's e-krona project - Report 1, September. 